\title{
How coaches' need-supportive and controlling behaviors are related to different (mal)adaptive outcomes in water polo players: a person-centered approach
}

\author{
Ángel Abós ${ }^{1}$ (D) - Miguel Murillo ${ }^{2} \cdot$ Javier Sevil-Serrano $^{2}$ (D) Luis García-González $^{2}$ (D)
}

Accepted: 9 July 2021

(C) The Author(s) 2021

\begin{abstract}
The relationship between both coaches' need-supportive and controlling behaviors and different athletes' motivational outcomes has been previously examined. However, little is known about the coexistence of coaches' need-supportive and controlling behaviors in the sports context and even less, about what coach's motivating style configuration may yield the most and the least adaptive pattern of outcomes in relation to athletes' motivating experiences. Grounded in self-determination theory (SDT), this study aimed to identify coach motivating style groups based on athletes' perceptions of need-supportive and four controlling behaviors (i.e., controlling use of rewards, negative conditional regard, intimidation, and personal control), and to examine their differences in terms of athletes' motivational outcomes and sport commitment. Using a sample of 658 young water polo players $\left(M_{a g e}=14.76, S D=1.36\right)$, results revealed five distinct coach motivating style groups. A coexistence of need-supportive and controlling use of rewards was identified among athletes in two groups. The "very low support-high control" group yielded the most maladaptive outcomes, while the "high support-low control" group was the most optimal style, even when compared to coaches that combined high need-supportive and controlling practices. This study provides deeper insights on how athletes may perceive simultaneously coach's need-supportive and controlling behaviors, and how some controlling practices imply a higher motivational cost among athletes.
\end{abstract}

Keywords Self-determination theory $\cdot$ Coach motivating style $\cdot$ Sport commitment $\cdot$ Cluster analysis

\section{Introduction}

Sport commitment decreases as the age of young athletes increases (Usán-Supervía et al., 2016). Although there are many

\section{Ángel Abós \\ aabosc@unizar.es \\ Miguel Murillo \\ mmurillo@unizar.es \\ Javier Sevil-Serrano \\ jsevils@unizar.es \\ Luis García-González \\ lgarciag@unizar.es}

1 Faculty of Social and Human Sciences, Physical Education and Physical Activity Promotion Research Group, University of Zaragoza, Calle Ciudad Escolar, 44003 Teruel, Spain

2 Faculty of Health and Sport Sciences, Physical Education and Physical Activity Promotion Research Group, University of Zaragoza, Plaza Universidad, 3, 22002 Huesca, Spain factors that might explain this decrease, one of the main causes is lack of motivation (Pulido et al., 2018). In that process, the motivating style adopted by the coach emerges as a determinant of athletes' motivation and sport commitment. According to self-determination theory (SDT) (Deci \& Ryan, 1985), coaches can adopt different behaviors to facilitate or undermine motivation of their athletes. On the one hand, they can involve athletes in decision-making, appraise their effort and progression, and try to make them feel part of the team (i.e., need-supportive style) (Rodrigues et al., 2020). On the other hand, they can also put pressure on athletes, punishing them, intimidating them, or controlling their lives (i.e., controlling style) (Bartholomew et al., 2010). While these coach styles can be conceptually well-separated (Bartholomew et al., 2011), emerging literature indicates that some coaches might simultaneously adopt both a need-supportive and controlling style (Haerens et al., 2018; Matosic \& Cox, 2014; Reynders et al., 2020). However, based on the athletes' perception, no studies have examined if coaches can simultaneously adopt a need-supportive style (i.e., including autonomy, competence, and relatedness support) and different features of controlling 
style (i.e., controlling use of rewards, negative conditional regard, intimidation, and excessive personal control). Moreover, the implications of these coach motivating style profiles in athletes' motivational outcomes and sport commitment have been explored very little to date. Relying on a person-centered approach, this study aims to contribute to the existing scientific literature by: (1) identifying different combinations of coach need-supportive and four controlling behaviors (i.e., controlling use of rewards, negative conditional regard, intimidation, and excessive personal control) that naturally emerge among water polo players, and (2) examining the extent to which the results of identified coach motivating style profiles are more or less optimal in terms of athletes' motivational experiences and sport commitment.

\section{Self-Determination Theory}

SDT (Deci \& Ryan, 1985) is one of the most commonly-used theories in the sport context to explain why people engage in sport activities (Teixeira et al., 2018). This theory sustains that human behavior is motivated by the satisfaction of three basic psychological needs (BPNs; autonomy, competence, and relatedness), which are essential for optimal psychological development and well-being (Ryan \& Deci, 2017). In the sport context, autonomy is satisfied when athletes realize that their actions depend on their own free will. Competence is satisfied when athletes have a perception of skill in the proposed activities. Finally, relatedness is satisfied when athletes feel connected with their teammates (Ryan \& Deci, 2017). In contrast, SDT posits that the frustration of these BPNs can trigger a less adaptive motivational development (Vansteenkiste \& Ryan, 2013). Autonomy is frustrated when athletes express a feeling of alienation in the activities carried out. Competence frustration occurs when athletes perceive a feeling of inadequacy to successfully solve the proposed activities. Finally, relatedness frustration occurs when athletes feel rejected within the team (Vansteenkiste \& Ryan, 2013). A large body of evidence has shown that athletes' satisfaction of these three BPNs is related to the more self-determined forms of motivation, while athletes' frustration of these BPNs is linked with the less selfdetermined forms of motivation (Murillo et al., 2018; Rodrigues et al., 2020).

SDT describes the internalization of behavior through a motivational continuum, which ranges from a higher to a lower level of self-determination as follow: intrinsic motivation, extrinsic motivation (i.e., integrated, identified, introjected, and external regulation), and amotivation (Deci \& Ryan, 1985). Given the high degree of self-determination of some extrinsic motivation regulations (i.e., integrated and identified regulation), some authors have suggested other ways of grouping these motivational regulations: autonomous motivation (i.e., intrinsic, integrated, and identified regulation), controlled motivation (i.e., introjected and external regulation), and amotivation (Haerens et al., 2018; Vansteenkiste et al., 2020). Athletes have an autonomous motivation when they enjoy sport, obtain a series of benefits from its participation, or it is in line with their lifestyle. Athletes have a controlled motivation when they participate in a sport to obtain rewards, recognition or approval, or to avoid a feeling of blame or punishment. Finally, amotivation appears when athletes do not see any reason to engage in sport (Ryan \& Deci, 2017). Prior research has indicated that athletes with high autonomous motivation are characterized by high sport commitment (García-Mas et al., 2010; O’Neil \& Hodge, 2020). In contrast, athletes who have controlled motivation or amotivation usually have less sport commitment (García-Mas et al., 2010; Pulido et al., 2018). Therefore, it seems important for athletes to develop high levels of self-determined motivation that will facilitate sport commitment and decrease sport dropout rates at early ages (O’Neil \& Hodge, 2020; Scanlan et al., 2016).

\section{Coaches' Motivating Style}

Coaches interact with their athletes in multiple ways, allowing them to satisfy or frustrate their BPNs and, consequently, to impact on their motivation and sport commitment (Ntoumanis et al., 2017). SDT suggests that this coach behavior can be understood in terms of two conceptually differentiated motivating styles. On the one hand, coaches can adopt a motivating style based on the support of the three BPNs of their athletes (i.e., need-supportive style) (Ryan \& Deci, 2017). Coaches support autonomy when they give athletes the chance to make choices and they facilitate decision-making. Coaches support competence when they value progress and adapt the difficulty of the tasks to the athletes' level. Finally, coaches provide relatedness support when they show interest in athletes' concerns and facilitate group cohesion (Pulido et al., 2018). This need-supportive style has been positively associated with BPN satisfaction and the more selfdetermined forms of motivation in athletes (Pulido et al., 2018; Rocchi et al., 2020; Rodrigues et al., 2020).

Coaches may also adopt a controlling style that seeks to make athletes think and act in a prescribed manner (Rodrigues et al., 2019; Ryan \& Deci, 2017). Previous studies have identified that this controlling style may be comprised of four conceptually different controlling behaviors (i.e., controlling use of rewards, negative conditional regard, intimidation, and excessive personal control) (Bartholomew et al., 2009; Matosic \& Cox, 2014). Coaches can have a controlling use of rewards when they use prizes to get athletes to behave in a certain way. Coaches can also implement negative conditional regard by taking less interest in the athletes when they are not satisfied with their actions. Further, coaches can intimidate by verbally humiliating athletes or assessing their performance in a non-constructive manner. Finally, coaches can adopt excessive personal control when they pry into aspects of their 
athletes' private lives or expect sport to be the center of their lives (Bartholomew et al., 2010). A large body of evidence in the context of sport has found a positive relationship between a controlling coach style and need frustration (Bartholomew et al., 2011; O'Neil \& Hodge, 2020). However, most of these studies assessed the coach controlling style based on a composite score of the four controlling behaviors. Consequently, the question how the four controlling coaching behaviors might yield distinct motivational outcomes for athletes has received far less attention (Matosic \& Cox, 2014). While the controlling practices of negative conditional regard, intimidation, and excessive personal control might be particularly harsh and intrusive because they target the athletes as a person, the controlling use of rewards might be less pressuring and damaging because it targets athletes' behavior (Bartholomew et al., 2009; Matosic \& Cox, 2014).

\section{Combinations of Coach Need-Supportive and Controlling Behaviors in Sport}

Grounded in SDT, research based on the relationship between coaches' motivating styles and athletes' motivational outcomes has been predominantly based on a variable-centered approach, which examines the relationship between different variables (Bartholomew et al., 2011; O'Neil \& Hodge, 2020; Rodrigues et al., 2020). In the present study, this body of research is extended by adopting a person-centered approach, which allows identifying groups of athletes who share similar characteristics of certain study variables. From a theoretical viewpoint, this approach makes it possible to examine whether a need-supportive style and the four controlling behaviors (i.e., controlling use of rewards, negative conditional regard, intimidation, and excessive personal control) represent widely separated constructs or, rather, some of them may interplay to different degrees. Moreover, identifying coach motivating style profiles characterized by a combination of a needsupportive style and the four controlling coaching behaviors can provide a better understanding about whether some controlling practices could produce some motivational benefits or if, on the contrary, they are always associated with more maladaptive patterns of outcomes. Although it has been extensively examined that controlling behaviors trigger maladaptive outcomes (e.g., boredom, sport dropout) (Bartholomew et al., 2011; O’Neil \& Hodge, 2020; Rodrigues et al., 2020), some coaches state that these controlling practices may be better than doing nothing. To illustrate, a previous study conducted by Matosic and Cox (2014) showed that the controlling use of rewards, when used in combination with autonomy-supportive strategies, might not be as detrimental in terms of athletes' BPN satisfaction and motivation. These preliminary results suggest that high need-supportive coach behaviors may act as a buffer against some controlling practices that can be used simultaneously by the coach.
Despite these potential contributions, only three studies (Haerens et al., 2018; Matosic \& Cox, 2014; Reynders et al., $2020)$, to date, have adopted a person-centered approach to identify coach motivating style profiles based on athletes' perception of some dimensions of need-supportive (i.e., autonomy or competence support) and controlling behaviors. Two of these studies (Haerens et al., 2018; Matosic \& Cox, 2014) included the coach's autonomy support but did not assess the coach's competence and relatedness support. More recently, Reynders et al. (2020), in addition to including coach's autonomy support, also included coach's competence support (i.e., two of the three BPN). Yet, this study did not examine the potential coexistence of autonomy and competence support together with controlling coaching behaviors, but rather it was examined in separate cluster analyses (i.e., by one hand the interplay between autonomy support and controlling behavior, and, on the other hand, the interplay between competence support and controlling behavior). In this sense, further studies are required to provide a more integrative picture of how a need-supportive style and the four controlling practices provided by the coaches are combined in the eyes of the athletes.

Regarding the identified profiles, the three previous studies found two different groups of coaches characterized by high autonomy support (Haerens et al., 2018; Matosic \& Cox, 2014; Reynders et al., 2020) or high competence support (Reynders et al., 2020) and low controlling style, and vice versa. In the study of Matosic and Cox (2014), the four controlling practices showed a uniform pattern in these two profiles. That is, when coach autonomy support was high, the controlling use of rewards, negative conditional regard, intimidation, and excessive personal control provided by the coach was low, and vice versa. However, they also identified a group of coaches that combined relatively high autonomy support (Haerens et al., 2018; Matosic \& Cox, 2014; Reynders et al., 2020) or high competence support (Reynders et al., 2020) and high controlling style, and the contrary (i.e., low autonomy or competence support-low control). More precisely, Matosic and Cox (2014) identified a group of coaches that combined high autonomy support and high controlling use of rewards with relatively low values in the rest of controlling coaching behaviors. Both Haerens et al. (2018) and Matosic and Cox (2014) revealed that athletes who perceived that their coaches were predominantly autonomy-supportive, showed the most optimal pattern of outcomes (i.e., greater BPN satisfaction and autonomous motivation), while the opposite was true in those athletes who perceived that their coaches preferably adopted a controlling style. In addition, Haerens et al. (2018) revealed that the group of high autonomy-supportive and low controlling style, was slightly more adaptive than the group characterized by combining high autonomy-supportive and controlling style values. Yet, neither Matosic and Cox (2014), nor Reynders et al. (2020) found significant differences between those groups. 


\section{The Present Study}

While it has been demonstrated that coaches can simultaneously adopt some dimensions of need-supportive behaviors (i.e., autonomy or competence support) and controlling behaviors to different degrees (Haerens et al., 2018; Matosic \& Cox, 2014; Reynders et al., 2020), the coexistence of different coach need-supportive behaviors (including autonomy, competence, and relatedness support) and the four controlling behaviors (i.e., controlling use of rewards, negative conditional regard, intimidation, and excessive personal control) has not been explored in the eyes of athletes to date. Likewise, research aimed at identifying which coach motivating styles profiles may yield the most and the least adaptive pattern of outcomes, in relation to athletes' motivational experiences and sport commitment, has received less attention. Therefore, based on athletes' perceptions, the first aim of the study was to identify a set of naturally occurring groups of coach motivating styles, characterized by different levels of a needsupportive style and four controlling behaviors (i.e., controlling use of rewards, negative conditional regard, intimidation, and excessive personal control). According to previous cluster studies, based on the athletes' perceptions of the combination of autonomy or competence support and controlling practices in coaches (Haerens et al., 2018; Matosic \& Cox, 2014; Reynders et al., 2020), at least two opposite coach motivating style groups were expected to be found (i.e., "high BPN support-low control" and "low BPN support-high control"). In those two groups, based on SDT and prior evidence (Matosic \& Cox, 2014), it was expected that the four controlling coaching behaviors would show a similar theoretical pattern (i.e., the four high or low). In addition, in line with Matosic and Cox (2014), two coach motivating styles that combined respectively high and low values of needsupportive and controlling use of rewards were also expected to be found (i.e., "high BPN support-high control rewards" and "low BPN support-low control rewards").

The second aim was to examine the extent to which the identified motivating style groups differed in terms of athletes' BPN satisfaction and frustration, types of motivation, and sport commitment. According to SDT and existing literature (Haerens et al., 2018; Matosic \& Cox, 2014; Reynders et al., 2020 ), the motivating style groups with a predominant presence of BPN support were expected to yield the most adaptive outcomes among athletes (i.e., greater BPN satisfaction, autonomous motivation, and sport commitment), while groups characterized by a predominant presence of controlling behaviors were expected to yield the most maladaptive outcomes (i.e., greater BPN frustration, controlled motivation, and amotivation). Finally, based on SDT (Ryan \& Deci, 2017), the motivating style group characterized exclusively by needsupportive behaviors was expected to yield a more optimal pattern of outcomes than the other possible group characterized by a high presence of both need-supportive and controlling use of rewards. However, according to Matosic and Cox (2014) there was also the possibility that there would be no differences between these two hypothesized profiles because controlling use of rewards is not too intrusively into athletes as a person and, therefore, they can perceive it as legitimate and normative within a sport team (Delrue et al., 2019).

\section{Method}

\section{Participants and Procedure}

A convenience sample of 658 Spanish water polo players, aged between 13 and 18 years $(M=14.76, S D=1.36$; $33.43 \%$ women), participated in this cross-sectional study. Study. The participants belonged to 43 sport clubs, from 13 different Spanish regions, distributed into different age groups: $49 \%(n=323)$ played in U-14 group, $42 \%(n=276)$ in U-16 group, and 9\% $(n=59)$ in U-18 group. Athletes trained an average of 4.79 days $(S D=0.75)$ and $11.64 \mathrm{~h}$ per week $(S D=4.62)$, and their sport experience ranged from 1 to 11 seasons $(M=4.85 ; S D=2.09)$.

In order to collect the data, the main researcher contacted with the Royal Spanish Swimming Federation (RFEN, Spanish acronym) to request their collaboration. With their agreement, the clubs participating in different Spanish championships were informed by e-mail about the study aims, asking them for their participation. Next, the clubs informed their players about the study, who, if they wished to participate, had to meet a written informed consent. Because participants were not legal age, this informed consent had to be completed also by their parents. Data were collected throughout the first competition day of each of the championships. Athletes were requested to complete the questionnaires in paper-and-pencil format, without the presence of their coaches. Before starting, athletes were reminded that the questionnaires were totally anonymous and their confidentiality was guaranteed. The time to compile the questionnaires was approximately 25-30 min. Ethical approval for this study was obtained from the University's research ethics committee.

\section{Measures}

Unless otherwise noted, athletes reported their agreement with the items on a 5-point Likert scale ranging from 1 (totally disagree) to 5 (totally agree).

\section{Perceived Need-Supportive Coach Behaviors}

Athletes' perceptions of their coaches' need-supportive behaviors were measured using an adaptation to water polo of 
the Questionnaire of Basic Psychological Needs Support (QBPNS) (Sánchez-Oliva et al., 2013). The QBPNS consists of 12 items (four items per factor) assessing competence (e.g., "Offers us activities based on our skill level"), autonomy (e.g., "Often asks us about our preferences with respect to the activities we carry out"), and relatedness support (e.g., "Encourages positive interactions among all pupils"). Each item begins with the stem: "In water polo, my coach...". In this study, consistent with SDT (Ryan \& Deci, 2017), and considering the large positive and significant associations between the three need-supportive behaviors $\left(r_{\text {autonomy-competence }}\right.$ support $=.79, p<.001 ; r_{\text {autonomy-relatedness support }}=.62, p<.001$; $r_{\text {competence-relatedness support }}=.74, p<.001$ ), cluster analyses were performed based on a composite score for parsimony reasons. In support of this decision, autonomy support $(r=.81, p<.001)$, competence support $(r=.78, p<.001)$, and relatedness support $(r=.78, p<.001)$ were also highly positively correlated with the composite score of BPN support. The confirmatory factor analysis (CFA) revealed a good fit to the data $\left(\chi^{2}(51)=192.954, p<.01 ; \mathrm{CFI}=.961\right.$; $\mathrm{TLI}=.949 ;$ RMSEA $=.066)$.

\section{Perceived Controlling Coach Behaviors}

Athletes' perceptions of their controlling coach behaviors were measured using the Spanish version of the Controlling Coach Behaviors Scale (CCBS) (Castillo et al., 2014). The CCBS includes 15 items that evaluate controlling use of rewards (e.g., four items: "The only reason my coach rewards/ praises me is to make me train harder"), negative conditional regard (e.g., four items: "My coach pays me less attention if I have displeased him/her"), intimidation (e.g., four items: "My coach shouts at me in front of others to make me do certain things"), and excessive personal control (e.g., three items: "My coach tries to control what I do during my free time"). Each item begins with the stem: "In my water polo team..." and responses were registered on a 7-point Likert scale ranging from 1 ("totally disagree") to 7 ("totally agree"). In this study, the four controlling behaviors were positively related to each other with moderate values (i.e., $r_{\text {average }}=.42, p<.01$, for further information, see Table 1). Considering these results, and in line with previous studies (Matosic \& Cox, 2014), the four controlling behaviors were examined separately in this research. The CFA showed a good fit to the data $\left(\chi^{2}(84)=240.449, p<.01 ;\right.$ CFI $=.936 ;$ TLI $=.920$; RMSEA $=.054)$.

\section{BPN Satisfaction}

Athletes' BPN satisfaction was measured using the Spanish version of the Motivating Mediators in Sports Scale (González-Cutre et al., 2007). This scale includes 23 items introduced by the stem "When I play water polo..." that assess competence (e.g., seven items: "I feel that I am among the most capable"), autonomy (e.g., eight items: "I feel I can make my own decisions"), and relatedness satisfaction (e.g., eight items "I feel good with the people I train with"). In this study, the CFA showed a good fit to the data $\left(\chi^{2}(206)=935.778, p\right.$ $<.01 ; \mathrm{CFI}=.911 ; \mathrm{TLI}=.904 ; \mathrm{RMSEA}=.076)$.

\section{BPN Frustration}

Athletes' BPN frustration was measured using the Spanish version in sport context of the Psychological Need Thwarting Scale (PNTS) (Sicilia et al., 2013). This scale consists of 12 items (four items per factor) assessing competence (e.g., "I feel frustrated because I am not given opportunities to fulfill my potential"), autonomy (e.g., "I feel obliged to follow training decisions made for me"), and relatedness frustration (e.g., "I feel other people dislike me"). Each item begins with the stem: "When I play water polo..." and responses were registered on a 7-point Likert scale ranging from 1 ("totally disagree") to 7 ("totally agree"). In this study, the CFA revealed a $\operatorname{good}$ fit to the data $\left(\chi^{2}(51)=98.188, p<.01\right.$; $\mathrm{CFI}=.986 ; \mathrm{TLI}=.982 ; \mathrm{RMSEA}=.040)$.

\section{Types of Motivation}

Athletes' motivation was measured using the Spanish version of the Sport Motivation Scale (SMS) (Balaguer et al., 2007), comprised of 28 items and seven factors (four items per factor) preceded by the stem "Why do you play water polo?". Three of these factors refer to different types of intrinsic motivation: to know (e.g., “...for the pleasure it gives me to know more about the sport that I practice"), to accomplish things (e.g., "...for the satisfaction I experience while I am perfecting my abilities"), and to experience stimulation (e.g., " “...for the pleasure I feel in living exciting experiences"). This scale also assesses: identified regulation (e.g., "...because it is one of the best ways I have chosen to develop other aspects of myself"), introjected regulation (e.g., “....because I must do sports to feel good about myself"), external regulation (e.g., “...to show others how good I am at my sport"), and amotivation (e.g., "...it is not clear to me anymore; I don't really think my place is in sport"). Consistent with SDT and previous studies (Haerens et al., 2018), average values of the three types of intrinsic motivation, integrated regulation, and identified regulation were used to calculate a composite score of autonomous motivation. Likewise, introjected and external regulation were also used to calculate a composite score of controlled motivation. In the present study, the three-factor CFA revealed a good fit to the data $\left(\chi^{2}(329)=704.726, p<.01\right.$; $\mathrm{CFI}=.974 ; \mathrm{TLI}=.970 ; \mathrm{RMSEA}=.043)$. 
Table 1 Reliability, means, standard deviations, and Pearson's correlations among the study variables

\begin{tabular}{|c|c|c|c|c|c|c|c|c|c|c|c|c|c|}
\hline & Study variables & $\alpha$ & $M(S D)$ & 1 & 2 & 3 & 4 & 5 & 6 & 7 & 8 & 9 & 10 \\
\hline 1. & Need-supportive behaviors & .83 & $3.78(0.57)$ & & & & & & & & & & \\
\hline 2. & Controlling use of rewards & .75 & $2.43(1.15)$ & $-.09^{*}$ & & & & & & & & & \\
\hline 3. & Negative conditional regard & .72 & $3.15(1.28)$ & $-.41^{* *}$ & $.31^{* *}$ & & & & & & & & \\
\hline 4. & Intimidation & .71 & $2.92(1.29)$ & $-.37^{* *}$ & $.36^{* *}$ & $.65^{* *}$ & & & & & & & \\
\hline 5. & Excessive personal control & .68 & $2.53(1.91)$ & $-.21^{* *}$ & $.33^{* *}$ & $.39^{* *}$ & $.52^{* *}$ & & & & & & \\
\hline 6. & BPN satisfaction & .86 & $4.25(0.52)$ & $.37^{* *}$ & $-.12^{* *}$ & $-.20^{* *}$ & $-.19^{* *}$ & $-.15^{* *}$ & & & & & \\
\hline 7. & BPN frustration & .84 & $2.85(1.01)$ & $-.35^{* *}$ & $.29^{* *}$ & $.45^{* *}$ & $.45^{* *}$ & $.34^{* *}$ & $-.48^{* * *}$ & & & & \\
\hline 8. & Autonomous motivation & .92 & $5.33(0.98)$ & $.35^{* *}$ & $-.08^{*}$ & $-.20^{* *}$ & $-.19^{* *}$ & $-.14^{* *}$ & $.45^{* * *}$ & $-.23^{* *}$ & & & \\
\hline 9. & Controlled motivation & .79 & 3.99 (1.19) & $.12^{* *}$ & $.15^{* *}$ & .03 & .04 & .07 & $.21^{* *}$ & .03 & $.46^{* *}$ & & \\
\hline 10. & Amotivation & .79 & $2.44(1.41)$ & $-.21^{* *}$ & $.28^{* *}$ & $.31^{* * *}$ & $.28^{* *}$ & $.29^{* *}$ & $-.42^{* *}$ & $.47^{* *}$ & $-.35^{* *}$ & $.08^{*}$ & \\
\hline 11. & Sport commitment & .80 & $4.43(0.70)$ & $.29^{* *}$ & $-.13^{* *}$ & $-.20^{* *}$ & $-.17^{* * *}$ & $-.22^{* *}$ & $.48^{* *}$ & $-.36^{* *}$ & $.51^{* *}$ & $.16^{* *}$ & $-.58^{* *}$ \\
\hline
\end{tabular}

${ }^{*}=p<.05 ;{ }^{* *}=p<.01$.

\section{Sport Commitment}

Athletes' sport commitment was measured using the Spanish version of the Sport Commitment Questionnaire (SCQ) (Sousa et al., 2007). Of the 28 items that comprise the SCQ, in the present study only the six items that assess the sport commitment factor were measured (e.g., "I am determined to continue practicing this sport next season"). In this study, the CFA showed a good fit to the data $\left(\chi^{2}(9)=17.991, p<.01\right.$; $\mathrm{CFI}=.995 ; \mathrm{TLI}=.991 ; \mathrm{RMSEA}=.040)$.

\section{Data Analyses}

First, descriptive statistics (i.e., mean $[M]$ and standard deviation $[S D])$, Cronbach's alpha reliabilities, and Pearson's correlations were calculated. Second, a cluster analysis was performed via a two-step procedure (i.e., hierarchical and nonhierarchical clustering methods), to identify different coach motivating style groups according to the scores obtained in BPN support and in the four controlling behaviors including in this study (i.e., controlling use of rewards, negative conditional regard, intimidation, and excessive personal control). As a prior step, the standardized values of the variables comprising the clusters were calculated. In addition, the athletes with values of more than three SD above or below the mean, or with high Mahalanobis values, were eliminated to reduce the impact of univariate and multivariate outliers, respectively (Steinley \& Brusco, 2011). In the first step, a hierarchical cluster analysis using Ward's method based on squared Euclidean distances were performed. Four to six solutions were tested. The theoretical explanation and percentage of explained variance for each solution were taken into account to identify the most optimal solution (Aguinis et al., 2013). In the second step, using the extracted cluster centers based on Ward's hierarchical method as non-random starting points, an iterative non-hierarchical k-means clustering procedure was performed. The stability of the retained cluster solution was examined using Cohen's Kappa (values of over .50 are acceptable) by means of double-split cross validation procedures. The athletes' gender and age group were examined as possible covariates through the chi-square test. Finally, a multivariate analysis of variance (i.e., MANOVA) with post-hoc tests (Bonferroni) was performed to examine differences between the retained groups and athletes' BPN satisfaction and frustration, types of motivation, and sport commitment. Effect sizes $\left(\eta_{\mathrm{p}}{ }^{2}\right)$ were considered small $(>.01)$, moderate $(>.06)$, and large (> .14), respectively (Cohen, 1988). All analyses were performed using SPSS v23.0 software.

\section{Results}

The descriptive statistics, reliability, and correlations of the study variables are reported in Table 1. BPN support was significantly and positively related to athletes' BPN satisfaction, autonomous motivation, controlled motivation, and sport commitment, while it was negatively related to the four controlling behaviors, BPN frustration, and amotivation. The four controlling behaviors were significantly and positively related to each other with moderate values. These controlling behaviors were significantly and negatively related to BPN satisfaction, autonomous motivation, and sport commitment, while the opposite was true for BPN frustration and amotivation. The only exception was controlling use of rewards, which showed a significant and positive relationship with controlled motivation. According to SDT, the remaining study variables showed, overall, significant relationships with each other.

Before conducting the cluster analysis, 25 outliers were removed (15 univariate and 10 multivariate), resulting in a final sample of 633 water polo players (33.93\% girls). Five 
significantly different clusters were identified, explaining a mean variance of $54 \%$ in the five dimensions of the clusters. The four-cluster solution was not retained because the explained variance was $<50 \%$ while the six-cluster solution was less theoretically interpretable than the five-cluster solution. For the retained five-cluster solution, the double-split cross-validation procedure provided an average Kappa value of .82, indicating excellent stability. The chi-square test revealed a non-significant cluster assignment by gender $\left(\chi^{2}\right.$ $[4]=6.31, p>.05)$, but it revealed a significant cluster assignment by age group $\left(\chi^{2}[8]=18.28, p<.05\right)$, which was included as a covariate in subsequent analyses.

The graphical results for the five-cluster solution, based on $\mathrm{Z}$ scores (Y-axis), with regard to BPN support, controlling use of rewards, negative conditional regard, intimidation, and excessive personal control are reported in Fig. 1. From left to right, the five clusters were characterized and labelled as follows: (1) the "high support-low control" group showed the highest values in BPN support, together with relatively low values in the four controlling style behaviors; (2) the "moderate support-control rewards" group showed moderate values in BPN support, relatively high values in the controlling use of rewards, and moderate to low values in the other controlling behaviors; (3) the "low support-low control" group showed relatively low values in all variables; (4) the "low supportmoderate control" group showed relatively low values in BPN support and controlling use of rewards, together with moderate values in negative conditional regard, intimidation, and excessive personal control; (5) the "very low support-high control" group showed the lowest values in BPN support together with the highest values in the four controlling behaviors.

Finally, differences between the retained groups regarding athletes' motivational outcomes and sport commitment were examined. The MANCOVA showed a significant multivariate effect with a high effect size $\left(F(44,2362.44)=46.21, p<.001, \eta_{\mathrm{p}}{ }^{2}=.448\right)$. Pairwise comparisons, F-values, and univariate effect sizes $\left(\eta_{\mathrm{p}}{ }^{2}\right)$ between the different groups are reported in Table 2 . Regarding athletes' need-based experiences, the "high support-low control" group showed the highest values in BPN satisfaction and the lowest values in BPN frustration, with the exception of the "moderate supportcontrol rewards" group in BPN satisfaction and the "low support-low control" group in BPN frustration. Regarding types of motivation, the "high support-low control" group displayed the highest values in autonomous motivation, while the "very low support-high control" group showed the lowest values. Yet, the differences between this group and the "low support-low control" and "low support-moderate control" groups, were not significant in terms of autonomous motivation. Further, none of the five groups differed in terms of controlled motivation. Finally, the "high support-low control" group showed significantly lower amotivation values than the other groups, with the exception of the
Fig. 1 Five-cluster solution based on Z-scores (Y axis) for needsupportive behaviors, controlling use of rewards, negative conditional regard, intimidation, and excessive personal control

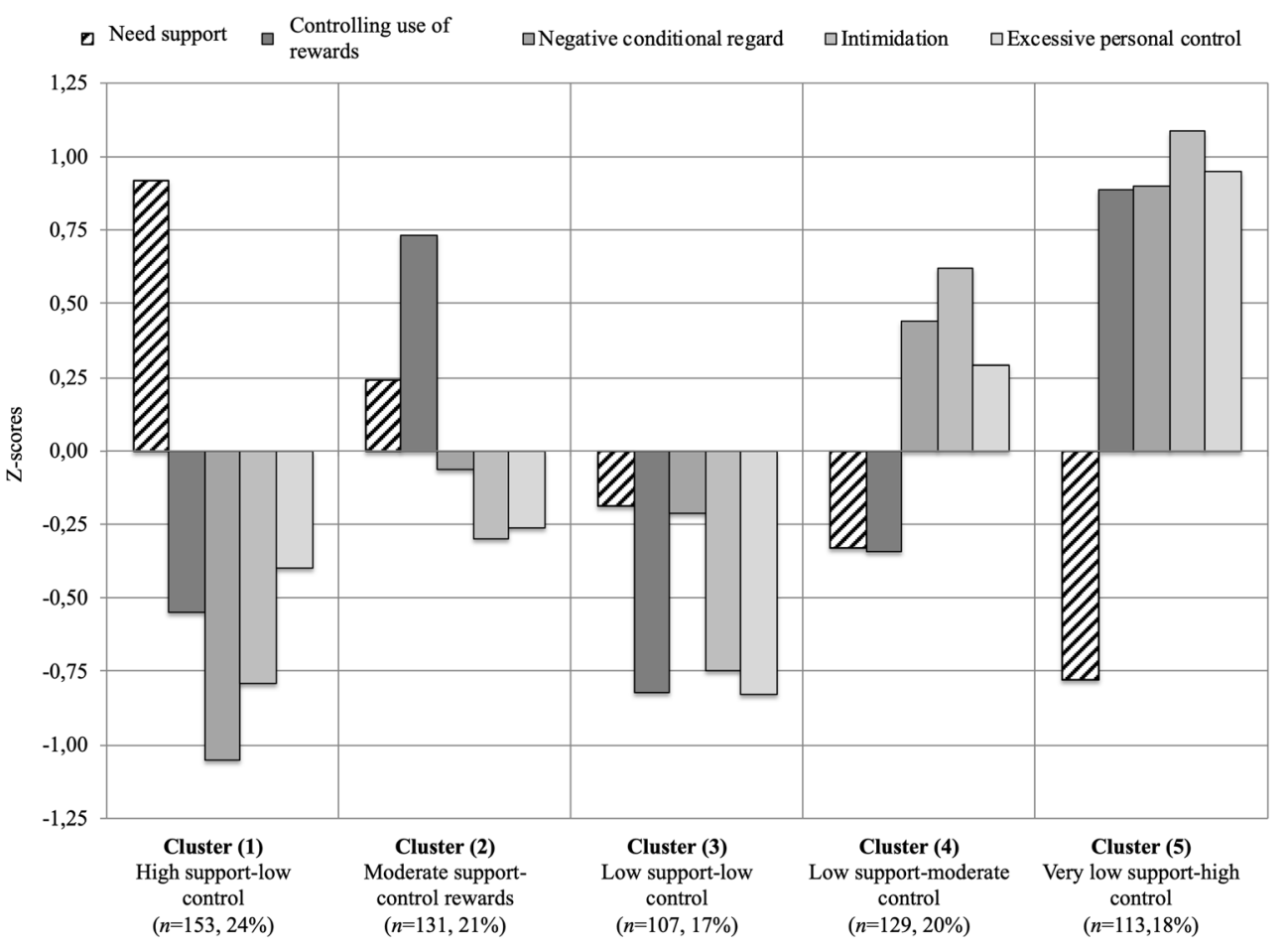


Table 2 Mean scores, differences, F-values, and effect sizes $\left(\eta_{\mathrm{p}}{ }^{2}\right)$ for study variables according to cluster membership

\begin{tabular}{|c|c|c|c|c|c|c|c|}
\hline \multirow[t]{2}{*}{ Variables } & \multirow{2}{*}{$\begin{array}{l}\text { Cluster (1) } \\
\text { High support-low } \\
\text { control } \\
n=153(24 \%)\end{array}$} & \multirow{2}{*}{$\begin{array}{l}\text { Cluster }(2) \\
\text { Moderate support-control } \\
\text { rewards } \\
n=131(21 \%)\end{array}$} & \multirow{2}{*}{$\begin{array}{l}\text { Cluster (3) } \\
\text { Low support-low } \\
\text { control } \\
n=107(17 \%)\end{array}$} & \multirow{2}{*}{$\begin{array}{l}\text { Cluster (4) } \\
\text { Low support-moderate } \\
\text { control } \\
n=129(20 \%)\end{array}$} & \multirow{2}{*}{$\begin{array}{l}\text { Cluster (5) } \\
\text { Very low support-high } \\
\text { control } \\
n=113(18 \%)\end{array}$} & \multirow[b]{2}{*}{$\mathrm{F}^{(4,627)}$} & \multirow[b]{2}{*}{$\eta_{\mathrm{p}}^{2}$} \\
\hline & & & & & & & \\
\hline & & & \multicolumn{3}{|l|}{ Cluster dimensions } & & \\
\hline \multicolumn{8}{|c|}{ Need-supportive behaviors } \\
\hline Z-scores & $0.92(0.05)^{\mathrm{a}}$ & $0.24(0.06)^{\mathrm{b}}$ & $-0.19(0.06)^{\mathrm{c}}$ & $-0.33(0.06)^{\mathrm{c}}$ & $-0.78(0.06)^{\mathrm{d}}$ & \multirow[t]{2}{*}{$102.03^{* *}$} & \multirow[t]{2}{*}{.39} \\
\hline $\begin{array}{l}\text { Raw scores } \\
(1-5)\end{array}$ & $4.32(0.03)^{\mathrm{a}}$ & $3.90(0.03)^{\mathrm{b}}$ & $3.64(0.04)^{c}$ & $3.55(0.04)^{\mathrm{c}}$ & $3.28(0.04)^{\mathrm{d}}$ & & \\
\hline \multicolumn{8}{|c|}{ Controlling use of rewards } \\
\hline Z-scores & $-0.55(0.05)^{\mathrm{a}}$ & $0.73(0.05)^{\mathrm{b}}$ & $-0.82(0.06)^{\mathrm{c}}$ & $-0.34(0.06)^{\mathrm{d}}$ & $0.89(0.06)^{\mathrm{b}}$ & \multirow[t]{2}{*}{$176.35^{* *}$} & \multirow[t]{2}{*}{.53} \\
\hline $\begin{array}{c}\text { Raw scores } \\
(1-7)\end{array}$ & $1.79(0.06)^{\mathrm{a}}$ & $3.36(0.06)^{b}$ & $1.47(0.07)^{\mathrm{c}}$ & $2.05(0.07)^{\mathrm{d}}$ & $3.56(0.07)^{\mathrm{b}}$ & & \\
\hline \multicolumn{8}{|c|}{ Negative conditional regard } \\
\hline Z-scores & $-1.05(0.04)^{\mathrm{a}}$ & $-0.06(0.06)^{\mathrm{b}}$ & $-0.21(0.05)^{\mathrm{b}}$ & $0.44(0.85)^{\mathrm{c}}$ & $0.90(0.06)^{\mathrm{d}}$ & \multirow[t]{2}{*}{$151.87^{* *}$} & \multirow[t]{2}{*}{.49} \\
\hline $\begin{array}{c}\text { Raw scores } \\
(1-7)\end{array}$ & $1.80(0.06)^{\mathrm{a}}$ & $3.14(0.07)^{\mathrm{b}}$ & $2.93(0.08)^{\mathrm{b}}$ & $3.80(0.08)^{\mathrm{c}}$ & $4.42(0.08)^{\mathrm{d}}$ & & \\
\hline \multicolumn{8}{|l|}{ Intimidation } \\
\hline Z-scores & $-0.79(0.05)^{\mathrm{a}}$ & $-0.30(0.05)^{\mathrm{b}}$ & $-0.75(0.06)^{\mathrm{a}}$ & $0.62(0.05)^{\mathrm{c}}$ & $1.09(0.04)^{\mathrm{d}}$ & \multirow[t]{2}{*}{$259.43^{* *}$} & \multirow[t]{2}{*}{.62} \\
\hline $\begin{array}{l}\text { Raw scores } \\
\quad(1-7)\end{array}$ & $1.91(0.07)^{\mathrm{a}}$ & $2.59(0.06)^{b}$ & $1.97(0.07)^{\mathrm{a}}$ & $3.85(0.07)^{\mathrm{c}}$ & $4.50(0.07)^{\mathrm{d}}$ & & \\
\hline \multicolumn{8}{|c|}{ Excessive personal control } \\
\hline Z-scores & $-0.40(0.05)^{\mathrm{a}}$ & $-0.26(0.04)^{\mathrm{a}}$ & $-0.83(0.05)^{\mathrm{b}}$ & $0.29(0.04)^{\mathrm{c}}$ & $0.95(0.06)^{\mathrm{d}}$ & \multirow[t]{3}{*}{$99.38^{* *}$} & \multirow[t]{3}{*}{.39} \\
\hline \multirow{2}{*}{$\begin{array}{l}\text { Raw scores } \\
\quad(1-7)\end{array}$} & $2.06(0.08)^{\mathrm{a}}$ & $2.25(0.08)^{\mathrm{a}}$ & $1.46(0.09)^{\mathrm{b}}$ & $3.02(0.09)^{\mathrm{c}}$ & $3.94(0.09)^{\mathrm{d}}$ & & \\
\hline & & & Athletes' outcomes & & & & \\
\hline \multicolumn{8}{|c|}{ BPN satisfaction } \\
\hline $\begin{array}{c}\text { Raw scores } \\
(1-5)\end{array}$ & $4.43(0.04)^{\mathrm{a}}$ & $4.30(0.04)^{\mathrm{ab}}$ & $4.24(0.04)^{b}$ & $4.21(0.04)^{\mathrm{b}}$ & $3.98(0.04)^{\mathrm{c}}$ & $12.87^{* *}$ & .08 \\
\hline \multicolumn{8}{|c|}{ BPN frustration } \\
\hline $\begin{array}{c}\text { Raw scores } \\
(1-7)\end{array}$ & $2.27(0.07)^{\mathrm{a}}$ & $2.87(0.07)^{\mathrm{bc}}$ & $2.58(0.08)^{\mathrm{ac}}$ & $3.07(0.08)^{\mathrm{b}}$ & $3.62(0.08)^{\mathrm{d}}$ & $39.46^{* *}$ & .20 \\
\hline \multicolumn{8}{|c|}{ Autonomous motivation } \\
\hline $\begin{array}{l}\text { Raw scores } \\
(1-7)\end{array}$ & $5.76(0.08)^{\mathrm{a}}$ & $5.40(0.07)^{\mathrm{b}}$ & $5.29(0.09)^{\mathrm{bc}}$ & $5.07(0.08)^{\mathrm{bc}}$ & $4.99(0.07)^{\mathrm{c}}$ & $12.78^{* *}$ & .08 \\
\hline \multicolumn{8}{|c|}{ Controlled motivation } \\
\hline $\begin{array}{c}\text { Raw scores } \\
(1-7)\end{array}$ & $4.04(0.09)^{\mathrm{a}}$ & $4.13(0.10)^{\mathrm{a}}$ & $3.80(0.10)^{\mathrm{a}}$ & $3.78(0.11)^{\mathrm{a}}$ & $4.19(0.11)^{\mathrm{a}}$ & $3.16^{*}$ & .02 \\
\hline \multicolumn{8}{|l|}{ Amotivation } \\
\hline $\begin{array}{c}\text { Raw scores } \\
(1-7)\end{array}$ & $1.93(0.10)^{\mathrm{a}}$ & $2.50(0.11)^{\mathrm{b}}$ & $2.02(0.11)^{\mathrm{ab}}$ & $2.52(0.11)^{\mathrm{b}}$ & $3.38(0.11)^{\mathrm{c}}$ & $21.31^{* * *}$ & .12 \\
\hline Sport commitı & ent & & & & & & \\
\hline $\begin{array}{c}\text { Raw scores } \\
(1-5)\end{array}$ & $4.63(0.05)^{\mathrm{a}}$ & $4.51(0.05)^{\mathrm{a}}$ & $4.45(0.05)^{\mathrm{a}}$ & $4.38(0.06)^{\mathrm{a}}$ & $4.10(0.06)^{\mathrm{b}}$ & $8.53^{* *}$ & .05 \\
\hline
\end{tabular}

All analyses were controlled by the athlete's age category. Standard errors are provided in parentheses. A cluster mean is significantly different from another mean when they have different superscripts

${ }^{*}=p<.05 ;{ }^{* *}=p<.001$

"low support-low control" group. Moreover, the "very low support-high control" group revealed the highest amotivation values. Regarding sport commitment, the "very low support-high control" group showed the lowest values. Yet, the other groups did not show any significant differences with each other.

\section{Discussion}

While three previous studies have empirically demonstrated that some dimensions of need-supportive coach behaviors and controlling practices may co-occur to different degrees (Haerens et al., 2018; Matosic \& Cox, 2014; Reynders et al., 2020), the 
co-occurrence of athletes' perceptions of coach need-supportive and the four features of controlling style (i.e., controlling use of rewards, negative conditional regard, intimidation, and excessive personal control) has not been explored to date. Likewise, there are few studies that have examined the most and the least optimal pattern of outcomes in the resulting coach motivating style profiles among athletes. To fill some of the gaps, the present study aimed (1) to identify different configurations of athletes' perceptions of their coaches' need-supportive and four controlling behaviors (i.e., controlling use of rewards, negative conditional regard, intimidation, and excessive personal control), and (2) to examine the extent to which the coach motivating style groups identified were more or less adaptive in a set of motivational outcomes and in sport commitment of young water polo players.

In an absolute sense, athletes perceived average moderateto-high values of BPN support $(M=3.78 / 5)$. In contrast, the values perceived in the four controlling behaviors were moderate-to-low for negative conditional regard $(M=3.15 / 7)$ and low for controlling use of rewards $(M=2.43 / 7)$, intimidation $(M=2.92 / 7)$, and personal control $(M=2.53 / 7)$. Overall, the athletes in this study predominantly perceived coach needsupportive behaviors and, to a lesser extent, the different controlling behaviors. Indeed, even in the "very low support-high control" group, the absolute BPN support values continued to be moderate (i.e., $M=3.28$ ). Given the considerable number of studies in the sport context that indicate the benefits of supporting athletes' BPNs (Chu \& Zhang, 2018; O'Neil \& Hodge, 2020), these high values could be interpreted as hopeful information for water polo young athletes to get selfdetermined motivation and high sport commitment. Moreover, it is important to note that "high", "moderate", and "low" terms of the different groups refer to values that are compared with the values of other athletes in this study. Therefore, the labels of the five groups must be understood as a question of gradation.

Regarding the first aim, five coach motivating style groups were identified using the water polo players' perceptions of their coach's need-supportive and four controlling behaviors (i.e., controlling use of rewards, negative conditional regard, intimidation, and excessive personal control). Importantly, the percentage of athletes represented in each one of the groups was quite even (i.e., between $17 \%$ and $24 \%$ ). In line with the three previous studies on coaches' motivational style groups based on a person-centered approach (Haerens et al., 2018; Matosic \& Cox, 2014; Reynders et al., 2020), and consistent with our hypothesis, a "high support-low control" group emerged. Further, also consistent with prior research degrees (Haerens et al., 2018; Matosic \& Cox, 2014; Reynders et al., 2020), and with our hypotheses, a "very low support-high control" group emerged, which was exactly the opposite to the previous group. In line with the notion that needsupportive and controlling behaviors may represent two clearly separate motivation styles (Bartholomew et al., 2011;
O'Neil \& Hodge, 2020; Rodrigues et al., 2020), these two groups seem to indicate that at least some athletes would barely perceive none of the four controlling behaviors when they perceive high need-supportive behaviors from their coaches and vice versa. Yet, these two groups represented only $44 \%$ of the total sample of athletes in this study.

In line with the three previous person-centered studies (Haerens et al., 2018; Matosic \& Cox, 2014; Reynders et al., 2020), and with our hypotheses, an interplay of coach need-supportive and controlling behaviors was also found in two of the five groups identified. That is, according to the athletes' perception, some coaches tend to combine BPN support with some controlling behaviors, especially the controlling use of rewards (i.e., the "moderate support-control rewards" group). Thus, it seems that coaches could facilitate decision-making, value effort and progress, and facilitate group cohesion (i.e., needsupportive behaviors) while, simultaneously, trying to maintain motivation and intensity through reward to athletes (i.e., controlling use of rewards). In support of this argument, and in line with Matosic and Cox (2014), the correlations results displayed that while BPN support was negatively and moderately related to three of the four controlling behaviors $(r=-.21$ to $-.41, p<.01)$, association with the controlling use of rewards was, in contrast, considerably lower $(r=-.09, p<.05)$. Consequently, it seems that coaches would find it difficult to combine BPN support with some controlling behaviors such as negative conditional regard, intimidation, or personal control, which may invade athlete's personality (Bartholomew et al., 2011). Yet, it appears to be slightly more likely for them to combine BPN support strategies at the same time as applying controlling use of rewards strategies. In line with Matosic and Cox (2014), this controlling practice could be more accepted by athletes because it focuses, instead of their personality, on their sport behavior. Likewise, consistent with Haerens et al. (2018) and Reynders et al. (2020), a "low support-low control" group was also identified. However, in the study of Matosic and Cox (2014), which also differentiated between the four controlling behaviors, this coach group characterized by athletes' perceptions of low values of BPN support and controlling behaviors did not emerge. These differences could be explained by the number of athletes, age groups, and groups retained in each study. While in this study five groups were identified in a sample of 633 young athletes, Matosic and Cox (2014) identified only three groups in a sample of 165 university student-athletes. Finally, a further group was identified where low BPN support and controlling use of rewards were combined with a moderate use of other controlling behaviors (i.e., the "low support-moderate control" group). All these findings suggest that it may be 
inaccurate to classify coaches exclusively as being needsupportive or controlling (Delrue et al., 2019; Reynders et al., 2020).

With regard to the second aim, consistent with hypotheses, the "high support-low control" group displayed the highest values in autonomous motivation, while the "very low support-high control" group displayed the lowest values in BPN satisfaction and sport commitment, and the highest values in BPN frustration and amotivation. These results are broadly in line with SDT, as well as with prior research on coach motivating style profiles (Haerens et al., 2018), highlighting the importance of not just supporting young athletes' BPNs, but also of avoiding the use of controlling behaviors to obtain an adaptive motivational development. In line with Bartholomew et al. (2011) it seems unlikely that young athletes may benefit in terms of motivational outcomes from guilt, intimidation or personal attack from their coaches.

According to SDT, another of our hypotheses reported that the group characterized predominantly by need-supportive behaviors (i.e., the "high support-low control" group) could show a slightly more adaptive pattern of outcomes than the group that combined high need-supportive and controlling use of rewards (i.e., the "moderate support-control rewards" group). It is noteworthy that no significant differences were noticed in BPN satisfaction and in sport commitment between the "moderate support-control rewards" group and the "high support-low control" group. Such findings are in line with the study of Matosic and Cox (2014), in which no significant differences were found in BPN satisfaction between the theoretically more adaptive group and the group that combined high autonomy support and the controlling use of rewards. Given controlling use of rewards impacts on athlete's behavior (Bartholomew et al., 2011), they could perceive that their coach's intention is always to improve their performance. Therefore, when controlling use of rewards adopted by coaches is accompanied with high need-supportive behaviors, does not seem to undermine athletes' need satisfaction and sport commitment. In support of this claim, Reynders et al. (2020) also did not find significant differences in athletes' autonomous motivation and engagement between coaches who predominantly supported autonomy or competence, with those who combined high autonomy or high competence support with high controlling behavior (i.e., domineering control). However, in the present study, and consistent with SDT (Ryan \& Deci, 2017), the "high support-low control" group displayed significantly higher values in autonomous motivation and lower values in BPN frustration and amotivation, when compared with the aforementioned "moderate support-reward control" group. All these results suggest that high need-supportive coach behaviors may act as a buffer against the simultaneous use of controlling use of rewards in terms of some athletes' motivational outcomes, but not in others. According to Haerens et al. (2018), it seems important to avoid any controlling behavior, however small it may be, because of the maladaptive outcomes it may have on young athletes. In support of this argument, if the other groups characterized by relatively low or very low need-supportive behaviors are observed (clusters 3,4 , and 5), it can be seen how, insofar as the controlling behavior values increase, the patterns of outcomes triggered in each group are more maladaptive, especially in sport commitment.

\section{Limitations and Future Directions}

Some limitations must be considered when interpreting these results. First, the cross-sectional design used in this study does not allow to know if the identified groups are maintained in time, or how these variations in need-supportive and controlling behaviors could affect young athletes' motivation and sport commitment. Future longitudinal or experimental studies are required to overcome this limitation. Second, given the convenience sample of water polo players, findings cannot be generalized. A new avenue of research is to replicate this study with a representative sample of athletes from different sports, addressing more age groups (e.g., U-10, U-12, etc.). Finally, the present study analyzed athletes' perceptions of coach need-supportive and four controlling behaviors. In future research, it would be interesting to complement this viewpoint with the coach perceptions of their own interpersonal style. The use of observational methodology to contrast coaches' and athletes' perceptions also opens up another study perspective.

\section{Conclusions}

The results found in two of the five motivating groups suggest, in the eyes of young water polo players, that need-supportive style and the controlling use of rewards might co-occur in coaches to different degrees, thereby constituting different motivating styles. Thus, coaches may adopt a motivating style that simultaneously combines need-supportive and controlling behaviors, or neither. On the other hand, the results suggest that coaches' motivating styles have a great influence on athletes' motivational experiences and sport commitment. Those athletes who perceived their coaches as being predominantly need-supportive or controlling, yielded more and less adaptive patterns of outcomes, respectively. Importantly, the results found in the "moderate supportcontrol rewards" group suggest that coaches' need-supportive behaviors could buffer against some adverse effects of controlling use of rewards. Likewise, athletes' perceptions of a high use of controlling coach behaviors, especially those related to negative conditional regard, intimidation, and control personal, seem to yield more maladaptive outcomes. In this sense, it also seems important for coaches to reduce both the frequency and intensity of these controlling behaviors. Overall, our results indicate that it is not only important for coaches to adopt a motivating style 
based on need-supportive behaviors, but also to avoid controlling behaviors (particularly when coaches do not use need-supportive behaviors), to obtain positive motivating experiences and sport commitment in young water polo athletes.

Acknowledgements The authors acknowledge the collaboration of the Royal Spanish Swimming Federation (RFEN, Spanish acronym) as well as all the clubs, players, and coaches involved in the study.

Authors' Contribution This manuscript has been read and approved by all the authors, the requirements for authorship as stated earlier in this document have been met, and each author believes that the manuscript represents honest work.

Ángel Abós (AA): data analysis, statistical analysis, interpretation of data, manuscript preparation, manuscript editing, revising the work critically for important intellectual content.

Miguel Murillo (MM): data collection, data entry, design, literature search, tool preparation, manuscript preparation, revising the work critically for important intellectual content.

Javier Sevil-Serrano (JSS): literature search, manuscript preparation, revising the work critically for important intellectual content.

Luis García-González (LGG): guarantor of this research work, concept of this study, data collection, manuscript preparation, revising the work critically for important intellectual content.

Funding Open Access funding provided thanks to the CRUE-CSIC agreement with Springer Nature.

\section{Declarations}

Conflict of Interest On behalf of all authors, the corresponding author states that there is no conflict of interest.

Informed Consent Informed consent was obtained from all individual participants included in the study.

Data Availability The datasets generated during and/or analysed during the current study are available from the corresponding author on reasonable request.

Open Access This article is licensed under a Creative Commons Attribution 4.0 International License, which permits use, sharing, adaptation, distribution and reproduction in any medium or format, as long as you give appropriate credit to the original author(s) and the source, provide a link to the Creative Commons licence, and indicate if changes were made. The images or other third party material in this article are included in the article's Creative Commons licence, unless indicated otherwise in a credit line to the material. If material is not included in the article's Creative Commons licence and your intended use is not permitted by statutory regulation or exceeds the permitted use, you will need to obtain permission directly from the copyright holder. To view a copy of this licence, visit http://creativecommons.org/licenses/by/4.0/.

\section{References}

Aguinis, H., Gottfredson, R. K., \& Joo, H. (2013). Best-practice recommendations for defining, identifying, and handling outliers. Organizational Research Methods, 16(2), 270-301. https://doi.org/ 10.1177/1094428112470848.
Balaguer, I., Castillo, I., \& Duda, J. L. (2007). Psychometric properties of the sports motivation scale in Spanish athletes. Revista Mexicana de Psicología, 24(2), 197-207.

Bartholomew, K. J., Ntoumanis, N., Ryan, R. M., \& ThøgersenNtoumani, C. (2011). Psychological need thwarting in the sport context: Assessing the darker side of athletic experience. Journal of Sport and Exercise Psychology, 33(1), 75-102. https://doi.org/ 10.1123/jsep.33.1.75.

Bartholomew, K. J., Ntoumanis, N., \& Thøgersen-Ntoumani, C. (2009). A review of controlling motivational strategies from a selfdetermination theory perspective: Implications for sports coaches. International Review of Sport and Exercise Psychology, 2(2), 215233. https://doi.org/10.1080/17509840903235330.

Bartholomew, K. J., Ntoumanis, N., \& Thøgersen-Ntoumani, C. (2010). The controlling interpersonal style in a coaching context: Development and initial validation of a psychometric scale. Journal of Sport and Exercise Psychology, 32(2), 193-216. https://doi.org/10.1123/jsep.32.2.193.

Castillo, I., Tomás, I., Ntoumanis, N., Bartholomew, K., Duda, J. L., \& Balaguer, I. (2014). Psychometric properties of the Spanish version of the controlling coach behaviors scale in the sport context. Psicothema, 26(3), 409-414. https://doi.org/10.7334/ psicothema2014.76.

Chu, T. L., \& Zhang, T. (2018). Motivational processes in sport education programs among high school students: A systematic review. European Physical Education Review, 24(3), 372-394. https://doi. org/10.1177/1356336X17751231.

Cohen, J. (1988). Statistical power analysis for the behavioral sciences. Lawrence Erlbaum Associates.

Deci, E. L., \& Ryan, R. M. (1985). Intrinsic motivation and selfdetermination in human behavior. Plenum. https://doi.org/10. 1007/978-1-4899-2271-7.

Delrue, J., Reynders, B., Broek, G. V., Aelterman, N., De Backer, M., Decroos, S., De Muynck, G. J., Fontaine, J., Fransen, K., van Puyenbroeck, S., Haerens, L., \& Vansteenkiste, M. (2019). Adopting a helicopter-perspective towards motivating and demotivating coaching: A circumplex approach. Psychology of Sport and Exercise, 40, 110-126. https://doi.org/10.1016/j. psychsport.2018.08.008.

García-Mas, A., Palou, P., Gili, M., Ponseti, X., Borras, P. A., Vidal, J., Cruz, J., Torregrosa, M., Villamarin, F., \& Sousa, C. (2010). Commitment, enjoyment and motivation in young soccer competitive players. The Spanish Journal of Psychology, 13(2), 609-616. https://doi.org/10.1017/S1138741600002286.

González-Cutre, D., Martínez-Galindo, C., Alonso, N., Cervelló, E., Conte, L., \& Moreno-Murcia, J. A. (2007). Implicit beliefs of ability and psychological mediators as predictor variables of self-determined. In J. Castellano \& O. Usabiaga (Eds.), Investigación en la actividad Fisica y el deporte II (pp. 407-417). Universidad del Pais Vasco.

Haerens, L., Vansteenkiste, M., De Meester, A., Delrue, J., Tallir, I., Vande Broek, G., Goris, W., \& Aelterman, N. (2018). Different combinations of perceived autonomy support and control: Identifying the most optimal motivating style. Physical Education and Sport Pedagogy, 23(1), 16-36. https://doi.org/10.1080/ 17408989.2017.1346070.

Matosic, D., \& Cox, A. E. (2014). Athletes' motivation regulations and need satisfaction across combinations of perceived coaching behaviors. Journal of Applied Sport Psychology, 26(3), 302-317. https:// doi.org/10.1080/10413200.2013.879963.

Murillo, M., Sevil, J., Abós, Á., Samper, J., Abarca-Sos, A., \& GarcíaGonzález, L. (2018). Analysis of the sport commitment of young waterpolists: A study grounded in self-determination theory. Revista Iberoamericana de Psicologia Del Ejercicio y El Deporte, 13(1), $111-119$. 
Ntoumanis, N., Quested, E., Reeve, J., \& Cheon, S. H. (2017). Need supportive communication: Implications for motivation in sport, exercise, and physical activity. In B. Jackson, J. Dimmock, \& J. Compton (Eds.), Persuasion and communication in sport, exercise, and physical activity (pp. 155-169). Routledge.

O'Neil, L., \& Hodge, K. (2020). Commitment in sport: The role of coaching style and autonomous versus controlled motivation. Journal of Applied Sport Psychology, 32(6), 607-617. https://doi. org/10.1080/10413200.2019.1581302.

Pulido, J. J., Sánchez-Oliva, D., Sánchez-Miguel, P. A., Amado, D., \& García-Calvo, T. (2018). Sport commitment in young soccer players: A self-determination perspective. International Journal of Sports Science and Coaching, 13(2), 243-252. https://doi.org/10. 1177/1747954118755443.

Reynders, B., Van Puyenbroeck, S., Ceulemans, E., Vansteenkiste, M., \& Broek, G. V. (2020). How do profiles of need-supportive and controlling coaching relate to team athletes' motivational outcomes? A person-centered approach. Journal of Sport and Exercise Psychology Exercise Psychology, 42(6), 452-462. https://doi.org/ 10.1123/jsep.2019-0317.

Rocchi, M. A., Guertin, C., Pelletier, L. G., \& Sweet, S. N. (2020). Performance trajectories for competitive swimmers: The role of coach interpersonal behaviors and athlete motivation. Motivation Science, 6(3), 285-296. https://doi.org/10.1037/mot0000156.

Rodrigues, F., Pelletier, L., Neiva, H. P., Teixeira, D. S., Cid, L., \& Monteiro, D. (2019). Initial validation of the Portuguese version of the interpersonal behavior questionnaire (IBQ \& exercise: Measurement invariance and latent mean differen exercise: Measurement invariance and latent mean differences. Current Psychology. https://doi.org/10.1007/s12144-019-00374-y.

Rodrigues, F., Teixeira, D. S., Neiva, H. P., Cid, L., \& Monteiro, D. (2020). The bright and dark sides of motivation as predictors of enjoyment, intention, and exercise persistence. Scandinavian Journal of Medicine and Science in Sports, 30(4), 787-800. https://doi.org/10.1111/sms.13617.

Ryan, R. M., \& Deci, E. L. (2017). Self-determination theory: Basic psychological needs in motivation, development, and wellness. Guilford Press.
Sánchez-Oliva, D., Leo, F. M., Amado, D., Cuevas, R., \& García-Calvo, T. (2013). Desarrollo y validación del cuestionario de apoyo a las necesidades psicológicas básicas en educación física. European Journal of Human Movement, 30, 53-71.

Scanlan, T. K., Carpenter, P. J., Simons, J. P., Schmidt, G. W., \& Keeler, B. (2016). The sport commitment model: Measurement development for the youth-sport domain. Journal of Sport and Exercise Psychology, 15(1), 16-38. https://doi.org/10.1123/jsep.15.1.16.

Sicilia, A., Ferriz, R., \& Sáenz-Álvarez, P. (2013). Spanish validation of the psychological needs thwarting scale in exercise. Psychology, Society, \& Education, 5(1), 1-19. https://doi.org/10.25115/psye. v5i1.493.

Sousa, C., Torregrosa, M., Viladrich, C., Villamarín, F., \& Cruz, J. (2007). The commitment of young soccer players. Psicothema, 19(2), 256-262.

Steinley, D., \& Brusco, M. J. (2011). Choosing the number of clusters in K-means clustering. Psychological Methods, 16(3), 285-297. https://doi.org/10.1037/a0023346.

Teixeira, D. S., Marques, M., \& Palmeira, A. L. (2018). Associations between affect, basic psychological needs and motivation in physical activity contexts: Systematic review and meta-analysis. Revista Iberoamericana de Psicologia Del Ejercicio y El Deporte, 13(2), 225-233.

Usán-Supervía, P., Salavera-Bordás, C., Murillo-Lorente, V., \& AbadMegías, J. J. (2016). Relationship between motivation, commitment and selfconcept in adolescent soccer players of different sport categories. Cuadernos de Psicología Del Deporte, 16, 199-209.

Vansteenkiste, M., \& Ryan, R. M. (2013). On psychological growth and vulnerability: Basic psychological need satisfaction and need frustration as a unifying principle. Journal of Psychotherapy Integration, 23(3), 263-280. https://doi.org/10.1037/a0032359.

Vansteenkiste, M., Ryan, R. M., \& Soenens, B. (2020). Basic psychological need theory: Advancements, critical themes, and future directions. Motivation and Emotion, 44(1), 1-31. https://doi.org/10.1007/ s11031-019-09818-1.

Publisher's Note Springer Nature remains neutral with regard to jurisdictional claims in published maps and institutional affiliations. 